\title{
Orchestrating learning analytics (OrLA): Supporting inter- stakeholder communication about adoption of learning analytics at the classroom level
}

\author{
Luis P. Prieto \\ Tallinn University, Estonia \\ María Jesús Rodríguez-Triana \\ Tallinn University, Estonia \\ École Polytechnique Fédérale de Lausanne, Switzerland \\ Roberto Martínez-Maldonado \\ University of Technology Sydney, Australia \\ Yannis Dimitriadis \\ Universidad de Valladolid, Spain \\ Dragan Gašević \\ Monash University, Australia
}

\begin{abstract}
Despite the recent surge of interest in learning analytics (LA), their adoption in everyday classroom practice is still slow. Knowledge gaps and lack of inter-stakeholder communication (particularly with educational practitioners) have been posited as critical factors for previous LA adoption failures. Yet, what issues should researchers, practitioners and other actors communicate about, when considering the adoption of an LA innovation in a particular context? We reviewed and synthesised existing literature on four focus areas related to LA, their adoption, implications for practice, and more general factors that have emerged as crucial when studying everyday classroom adoption of technologies (i.e., classroom orchestration). This synthesis resulted in two conversational frameworks and an inter-stakeholder communication tool. These can be used to guide and support conversations and decisionmaking about the adoption of LA innovations. We illustrate their usefulness with examples of use in ongoing LA adoption processes in Australia, Spain and Estonia.
\end{abstract}

\section{Introduction}

Siemens and Long (2011) define learning analytics (LA) as "the measurement, collection, analysis and reporting of data about learners and their contexts, for purposes of understanding and optimising learning and the environments in which it occurs" (p. 34). LA, as a research field, has experienced an explosive growth since 2011, and is increasingly popular as an approach to inform everyday teaching and learning practice at all educational levels (Gašević, Dawson, \& Siemens, 2015). However, the adoption of LA innovations in everyday classroom practice is still slow (Ali, Asadi, Gašević, Jovanović, \& Hatala, 2013; Ferguson et al., 2014, 2016).

A number of researchers have started looking more systematically at the challenges of adopting LA from an institutional or strategic point of view (Colvin et al., 2015; Gašević, Dawson, \& Pardo, 2016; Tsai \& Gasevic, 2017; Tsai, Moreno-Marcos, Tammets, Kollom, \& Gašević, 2018). One of the crucial challenges for adoption that this growing body of literature identifies, is the lack of communication among stakeholders, and the knowledge gaps that some of them (particularly educational practitioners, including technical specialists and other classroom-level support staff) may have about the LA innovations to be integrated in their classroom practice (Colvin et al., 2015; Ferguson et al., 2014; Gašević et al., 2016; Macfadyen \& Dawson, 2012; Macfadyen, Dawson, Pardo, \& Gasevic, 2014; Tsai \& Gasevic, 2017). Conversely, LA researchers, technology developers and institutional leaders may not be aware of the implications of their proposed 
innovations for everyday classroom practice (Tsai et al., 2018). This dialogue, however, does not often emerge spontaneously and may need to be supported.

We address the challenge of supporting inter-stakeholder communication during the process of adopting an LA innovation, by structuring the content of this potential dialogue. More concretely, we tackle the research question: what issues should researchers, practitioners and other actors communicate about when considering the adoption of an LA innovation in a particular context? To respond to this question, it is critical to recognise that slow adoption is not exclusive to LA technology. For the last decade, researchers have been looking at how educational technology impacts everyday teaching and learning practice and the severe constraints under which such practice unfolds. This strand of research is often referred to as designing for classroom orchestration(Dillenbourg, 2013; Roschelle, Dimitriadis, \& Hoppe, 2013), "the process of productively coordinating supportive interventions across multiple learning activities occurring at multiple social levels" (Dillenbourg, Järvelä, \& Fischer, 2009, p. 12). Thus, to ensure successful adoption, LA technologies need to be orchestrable(i.e., compatible with classroom-level constraints and practices; see Tchounikine, 2013), and the issues that are important in orchestration research (which represent the point of view of practitioners, students and other actors in everyday classroom life) are likely to be an important part of the inter-stakeholder dialogue about adopting a certain LA innovation in a particular educational context.

To provide a conceptual framework for these conversations, we reviewed literature on several topics related to the followingquestions: What are LA, and how do we conceptualise them?How do LA impact practitioners' activities?How are LA adopted? What aspects make an educational technology easy to adopt in the classroom (i.e., orchestrable)? This breakdown is represented graphically in Figure 1.

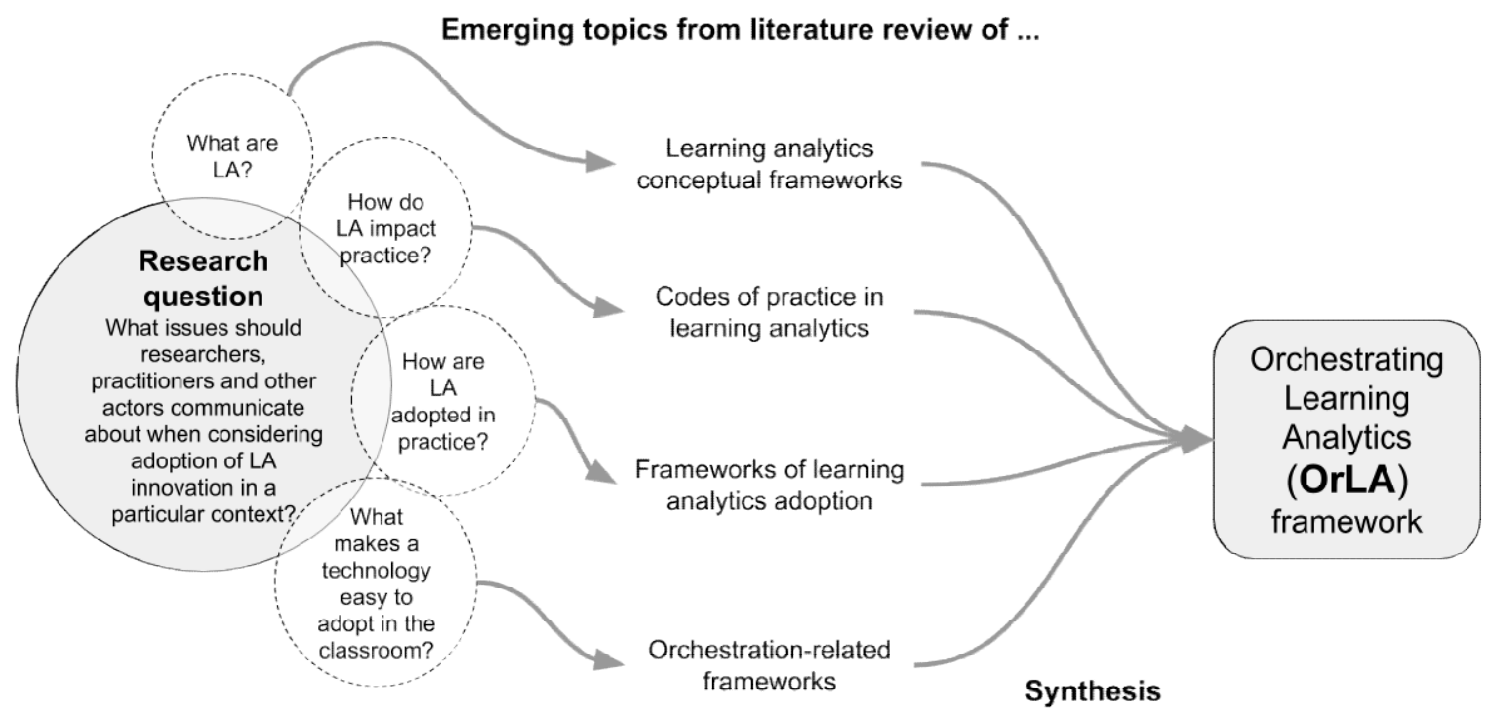

Figure 1. Research question and literature review topics from which the OrLA framework emerges

The following section describes a literature review of these four topics. Later on, we present the other main contribution of this paper: a synthesis of the issues uncovered, in the form of two conceptual frameworks to scaffold inter-stakeholder dialogue about LA adoption at the classroom level. We also present a conversational tool derived from these frameworks, and three illustrative examples of ongoing use of these tools and frameworks in Australia, Spain and Estonia. We conclude the paper with a discussion of theoretical and practical implications, as well as the outlook of this research line. 


\section{Orchestration and learning analytics: A review of literature}

\section{Review method}

To understand what topics and issues are important in the communication among stakeholders regarding the adoption of an LA innovation at the classroom level, we reviewed and analysed literature sources in selected topics of LA and orchestration-related research (Figure 1). Given the breadth of these two fields, which exceeds the scope of our research question, we focused on four categories of papers:

- LA conceptual frameworks have been reviewed to understand what issues are generally important in LA research and how LA innovations are conceptualised.

- LA codes of practice proposed by institutions to guide practitioners have been reviewedto understand how LA should be applied in everyday practice.

- LA adoption papers (beyond particular institutions' case studies) have been reviewed to understand what aspects are important in the process of LA adoption.

- Orchestration-related frameworks (beyond the account of particular empirical studies or educational technology adoption efforts) have been reviewed to understand how classroom orchestration may be applicable to LA innovations.

The analysed literature sources were sampled from the main publications for each of these areas: for LA, the Learning Analytics and Knowledge (LAK) conference proceedings and the Journal of Learning Analytics; for orchestration, the scientific workshops organised around the topic between 2011 and 2015, and the special section on the topic published in the Computers and Education journal. Additional sources have been taken from queries to databases such as Google Scholar, intended to capture grey literature(Kitchenham, 2004) and other sources that may have been overlooked. The initial literature search was performed in February-April 2016, and 33 papers were included in the analysis. An additional search was performed in November 2017, when five more recent sources were added. The review was performed by a team comprised of four of the five authors. The inclusion criteria required papers to be aligned with at least one of the four paper categories outlined above. The procedure to analyse these papers included the extraction of the following items from each paper (by three of the team members): the main contribution of the paper, its scope of application (e.g., learning context), the main needs or questions it addressed, and an open coding of the aspects (i.e., issues) that the contribution identified. In a second round of analysis, the four reviewers together sought full agreement on the list of aspects, merging synonyms and very similar aspects. In a third round, aspects were clustered in a bottom-up fashion (i.e., joining very similar aspects) into 23 overall topics. These 23 topics were then clustered again into larger themes, in two ways: as a theory-driven, researcher-oriented framework; and as a simplified framework for use by other stakeholders (see full descriptions of these frameworks in the following section). Figures 2 and 4 represent this topic clustering process graphically. Below we provide a brief summary of the reviewed literature sources and the main topics they tackle, as extracted from our analysis. This topical account is structured in paragraphs for each theme in the aforementioned simplified framework.

\section{LA literature: Frameworks, codes of practice and adoption}

\section{LA conceptual frameworks}

LA innovation. Since its establishment around 2011, the LA research community has worked intensively to define its goals, the main processes, and the most important aspects. These self-reflection efforts, materialised into conceptual frameworks, are fundamental to conceptualise and communicate the potential of LA innovations with the stakeholders that are to adopt them. Some of these frameworks have focused on addressing stakeholders' concerns, such as the kinds of support provided by LA solutions, comparing different LA systems, or suggesting how to choose among LA systems (Bakharia et al., 2016; Cooper, 2012; Siemens \& Baker, 2012). Other frameworks have touched upon the underlying assumptions of an LA innovation (Cooper, 2012) or, more broadly, the rationale behind an innovation (Cooper, 2012; EminMartinez et al., 2014). Another set of contributions have suggested the need for guidelines for the design of 
LA technologies (Knight \& Anderson, 2016; Martinez-Maldonado et al., 2016; McPherson, Tong, Fatt, \& Liu, 2016).

LA-enhanced orchestration. Another important aspect that LA frameworks can help us understand is how everyday educational practice at the classroom level (i.e., the classroom's orchestration) can be affected by introducing these innovations. Most commonly, LA frameworks have emphasised pedagogical guidelines for using LA solutions effectively (Drachsler \& Greller, 2016; Emin-Martinez et al., 2014; Greller \& Drachsler, 2012; Steiner, Kickmeier-Rust, \& Albert, 2016). Other frameworks have focused on the kinds of affordances offered by LA solutions, and the actionability of LA insights (Vatrapu, 2012).

Local constraints and challenges. Another group of LA frameworks has focused on the interaction between LA and local constraints and challenges. Such contextual constraints are mentioned by several authors (Drachsler \& Greller, 2016; Greller \& Drachsler, 2012; Steiner et al., 2016), with special emphasis on the expectations that stakeholders (e.g., teachers, students) may have on LA and their outcomes (Drachsler \& Greller, 2012). Other frameworks have stressed the support or facilitation that can be available in the local context (e.g., training, rewards, institutional support), which can make LA more effective and the adoption more appealing (Davenport, Harris, \& Morison, 2010). Multiple LA frameworks have also highlighted the importance of taking into account teacher-specific (and other stakeholder-specific) challenges, such as insufficient data literacy, beliefs, and attitudes (Davenport et al., 2010; Greller \& Drachsler, 2012; Vatrapu, 2012).

Cost-benefit appraisal. As in many other areas of technology adoption, among the LA frameworks included in the review there exists the implicit assumption that an appraisal of costs and benefits of an LA innovation can be instrumental for its adoption. Several frameworks have highlighted the importance of evaluating LA (Papamitsiou \& Economides, 2014; Willis III, Campbell, \& Pistilli, 2013), with multiple authors explicitly acknowledging the innovation's added value for student learning, as the main indicator to be ascertained in such evaluations and appraisals (Greller \& Drachsler, 2012; Papamitsiou \& Economides, 2014; Willis III et al., 2013). Others have mentioned the synergies with the existing socio-technical ecosystem as also important in such evaluations (Bakharia et al., 2016).

Ethics and privacy issues. Finally, it should be noted that another common theme appearing in the analysed LA frameworks is the emphasis on ethics and privacy issues (Drachsler \& Greller, 2016; Steiner et al., 2016). For instance, several authors have highlighted the inclusion of users (e.g., teachers, students) in the design process of LA innovations, as a way to achieve more responsible LA innovations (Knight \& Anderson, 2016; McPherson et al., 2016).

\section{LA codes of practice}

Ethics and privacy issues. Several codes of practice have been put forward by different authors and institutions to guide researchers and practitioners in the application of LA to formal education. Many of these codes of practice have a strong focus on ethics and privacy in the application of LA (Pardo \& Siemens, 2014; Rodríguez-Triana, Martínez-Monés, \& Villagrá-Sobrino, 2016; Sclater, 2014; Sclater \& Bailey, 2015; Slade \& Prinsloo, 2013).

Cost-benefit appraisal. Ethics, however, is not the only topic covered by these codes of practice. We can also find references to the aforementioned appraisal of costs and benefits of LA, indicating the importance of engaging practitioners and other stakeholders so that they can clearly see the potential and trade-offs of LA (Gunn et al., 2015). Others have also mentioned how finding synergies with existing technologies and practices can also be key in better perceiving the benefits of LA (Rodríguez-Triana et al., 2016).

Innovation and LA-enhanced orchestration. Several codes of practice also emphasise different aspects of the LA innovation, particularly proposing technology design guidelines (Gunn et al., 2015). Pedagogical guidelines are also mentioned in these codes of practice, related both to the use of the technology and the resulting LA-enhanced pedagogical practices (Pardo \& Siemens, 2014; Sclater, 2014; Sclater \& Bailey, 2015; Slade \& Prinsloo, 2013; Wise, 2014). 
Local constraints and challenges. It is worth mentioning that contextual constraints and challenges (from identifying meaningful data sources, to adapting the solutions to the local workload limitations and learning goals) feature prominently in some of these sources as well (Rodríguez-Triana et al., 2016).

\section{LA adoption}

Adoption. After a few initial years in which LA was considered a novel, emergent approach, LA researchers are now considering the adoption in actual practice as a critical issue for the field, in the sense of large-scale or institutional adoption (as noted in the Introduction), but also at the classroomlevel (Ali et al., 2013; Colvin et al., 2015; Gašević et al., 2016; Tsai \& Gasevic, 2017). Among the LA literature sources that explicitly address this kind of adoption, we found authors highlighting the costs and benefits that have to be well understood by stakeholders for such an adoption to occur, especially in terms of the added value of LA for learning (Colvin et al., 2015; Gašević et al., 2016; Tsai \& Gasevic, 2017) and the importance of evaluating LA innovations to more clearly ascertain these benefits (Ali et al., 2013; Colvin et al., 2015; Gašević et al., 2016; Tsai \& Gasevic, 2017). These adoption-oriented sources discuss many of the issues mentioned in more general LA frameworks, such as the importance of addressing privacy and ethical issues as a necessary stepping stone towards adoption (Gašević et al., 2016). They also pay attention to how the LA innovation is conceptualised, for example, regarding its assumptions (Colvin et al., 2015) and rationale (Gašević et al., 2016), and how compatible they are with the local context.

Local constraints and challenges. Referring to the influence of local constraints and challenges as critical factors for adoption (Gašević et al., 2016), several authors find that institutional support, facilitation or training are critical to achieve local adoption (Colvin et al., 2015; Gašević et al., 2016; Tsai \& Gasevic, 2017). This institutional support can also be instrumental in tackling teacher-specific challenges,such as data literacy, which are recognised as one of the main hurdles for LA adoption (Colvin et al., 2015; Gašević et al., 2016; Tsai \& Gasevic, 2017). We can see that these sources are addressing topics of educational practice at the classroom level (i.e., orchestration-related issues): taking into account the existing orchestration before the introduction of LA (e.g., in terms of actors and roles), as well as how LA change these roles (Colvin et al., 2015). More generally, pedagogical guidelines on the effective use of LA are considered necessary for their sustainable adoption (Colvin et al., 2015; Gašević et al., 2016; Tsai \& Gasevic, 2017).

\section{Orchestration-related frameworks}

Adoption. Adding to the aforementioned issues and topics detected in the LA literature, and especially the newlyemerging sources focused on the adoption of these innovations, we looked at previous work on orchestration, which defines critical issues that can affect the adoption of educational technology, and how it can be designed so that it is more easily adopted at the classroomlevel (Dillenbourg, 2013; Dimitriadis, Prieto, \& Asensio-Pérez, 2013; Nussbaum \& Diaz, 2013; Prieto, Wen, Caballero, \& Dillenbourg, 2014; Terzis \& Economides, 2011).

Local constraints and challenges. A good amount of this orchestration-related literature emphasises the design of educational technologies that fit the very restrictive constraints and challenges that teachers (and students) commonly face in everyday practice, for example, in terms of time, attention, energy, and cognitive resources (Dillenbourg, 2013; Prieto, Dimitriadis, Asensio-Pérez, \& Looi, 2015; Prieto, Holenko-Dlab, Abdulwahed, Gutiérrez, \& Balid, 2011). They also highlight other means of support and facilitation (e.g., lesson plans, guidelines of technology usage) as crucial for effective adoption of any classroom technology (Dimitriadis et al., 2013; Nussbaum \& Diaz, 2013; Terzis \& Economides, 2011). Innovations that are adapted to teacher-specific challenges are more likely to succeed (Prieto et al., 2015, 2011; Terzis \& Economides, 2011); other authors also consider the users' perception of the technology as critical for adoption (Terzis \& Economides, 2011).

Cost-benefit appraisal. Similarly to what we found in the LA literature, in orchestration-related sources the cost-benefit appraisal of the innovation is identified as critical, with several authors focusing on how to evaluate an innovation from the point of view of its impact on the classroom orchestration by practitioners (Nussbaum \& Diaz, 2013; Prieto et al., 2014; Terzis \& Economides, 2011). Similarly, several authors 
highlight that the main focus of these evaluations should be the added value for student learning (Phiri, Meinel, \& Suleman, 2016; Terzis \& Economides, 2011), even if the affective aspects and social value of the innovations are also recognised as important (Terzis \& Economides, 2011).

Innovation. One of the main topics in which orchestration research has made significant advances (i.e., where much of its added value lies, compared to the LA literature) is in providing tools and frameworks to conceptualise learning technology innovations, for instance, by establishing design guidelines for orchestrable (i.e., more easily adoptable) classroom technologies (Cuendet, Bonnard, Do-Lenh, \& Dillenbourg, 2013; Dillenbourg, 2013; Dimitriadis et al., 2013; Phiri et al., 2016; Prieto et al., 2014; Sharples, 2013). These guidelines (which highlight values such as minimalism, teacher control, usability at a classroom level and learners' experience) can also be very useful for LA technology and innovation design (Terzis \& Economides, 2011). Orchestration-related literature promotes the comparison of a particular educational technology in different contexts (Tchounikine, 2013), which can also contribute to strengthening the evidence of impact of LA tools.

Current orchestration. Another area where orchestration-related literature can add value to LA, is in providing tools to characterise orchestration both before and after the introduction of an innovation: defining the activities and tasks that classroom orchestration entails (Dillenbourg, 2013; Phiri et al., 2016; Prieto et al., 2015, 2011; Tchounikine, 2013), or the importance of actors and roles (i.e., who performs each of these tasks) and how the innovation changes these roles (Prieto et al., 2015, 2011). In this regard, certain works on orchestration have also provided pedagogical guidelines that may support the adoption of a technology for a particular pedagogical purpose (Dimitriadis et al., 2013; Hämäläinen \& Vähäsantanen, 2011; Nussbaum \& Diaz, 2013).

\section{Orchestrating Learning Analytics (OrLA) frameworks}

The literature review above identified up to 23 different topics that can be crucial for the process of adoption of LA at the classroom level. To distil this long list of topics into a more manageable and memorable set of themes, we further clustered them in two ways, which can be useful for different purposes and stakeholders.

\section{The theory-driven view}

In a first attempt to understand which issues are critical in the process of LA adoption (and communicating with classroom-level stakeholders about it), we resorted to sociocultural activity theory (as reformulated by Engeström, 1987) to structure the results of our literature review. This theoretical underpinning is widely recognised by the research community and has been specifically targeted at human activities that involve some kind of change and tensions (clearly the case of LA adoption). According to Engeström's conception, human activity systems involve one or more human actors (subject) acting towards a goal (outcome), by producing objects (in a very general sense, including also knowledge or experiences). This production is mediated primarily by tools. However, the activity is also embedded in a sociocultural context that involves a wider community, with its own rules and division of labour.

We therefore mapped the aforementioned 23 topics into Engeström's (1987) classic structure. Given our focus on classroom-level adoption of LA, we can consider practitioners as the main subjects of the activity (although it could be extended to focus also on students). These subjects use a series of tools (both conceptual and technological) to perform their teaching or learning practice (the object of the activity). By changing some of these tools (e.g., by adopting an LA innovation), such practices evolve towards a new LA-enhanced practice (the outcome). The proposed framework also recognises the mediating role of contextual aspects (rules, community, division of labour). Figure 2 represents how we came from the four categories of literature in our review (top layer) and the 36 analysed papers (second layer) to the 23 emergent topics (third layer) and the seven elements of Engeström's activity system (bottom layer). 


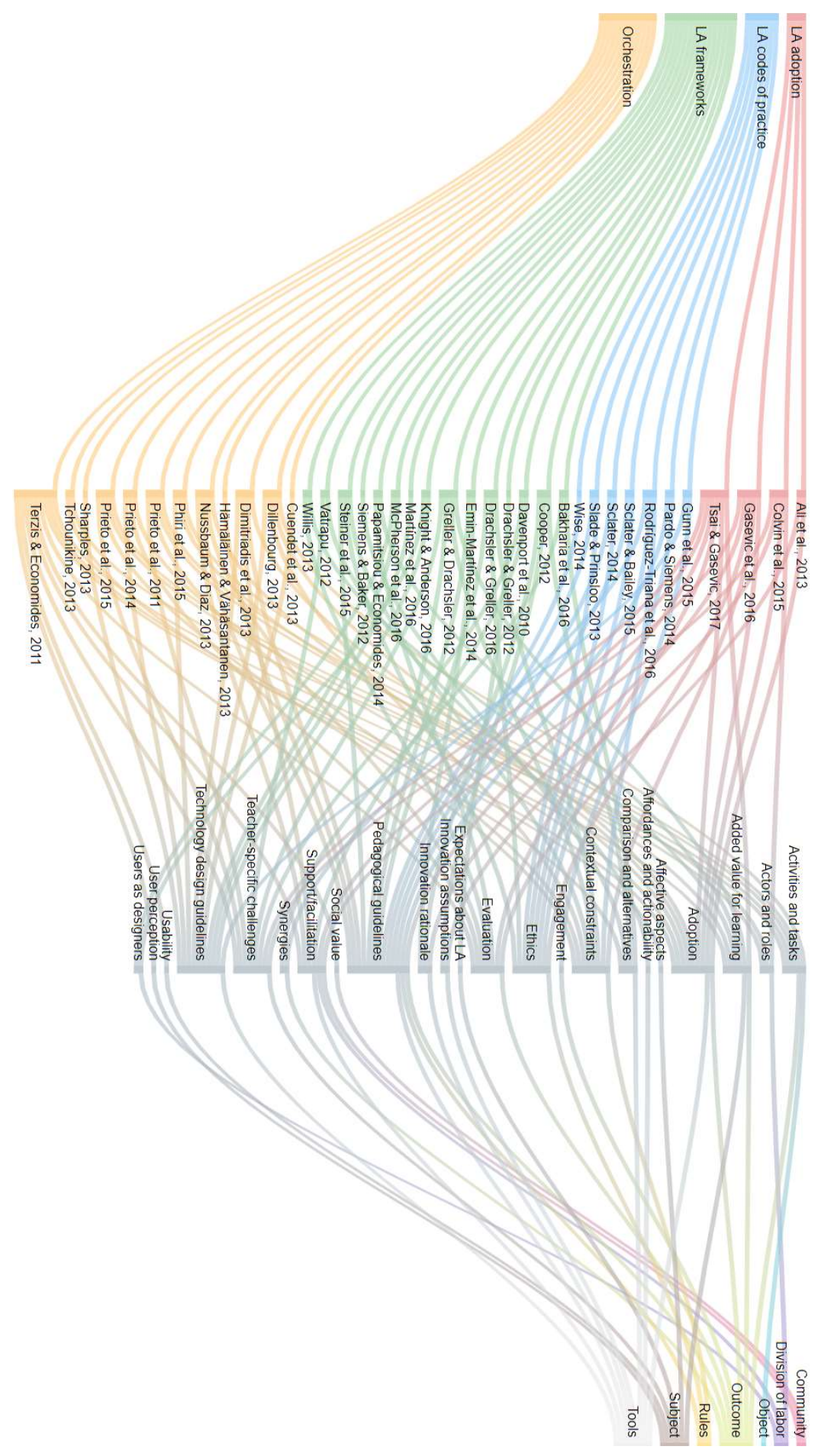

Figure 2. Literature review and topical mapping to Engeström's (1987) sociocultural activity theory notions. A larger, interactive version is available at https://prisan-tlu.shinyapps.io/sankeyDiagrams/. 
Thus, we arrive at an activity-theoretical depiction of LA adoption, along with important topics to understand each of the elements of the activity system (Figure 3). There, we can see, for example, that it is crucial to understand not only the novel affordances of the LA innovation, but also how this newlyintroduced element involves costs (e.g., in terms of time and effort) and modifies the mediating role that the rest of the technologies used in the classroom ecosystem have (see the tools element at the top of Figure 3). This first conceptual framework can be especially useful for researchers for focusing their investigation of an LA adoption process (e.g., designing or evaluating such a process), but also their communication with other stakeholders during the process (see the stakeholder forms and usage examples later on in this paper).

\section{The simplified view}

One disadvantage of the conceptual framework presented above is that it requires a certain understanding of activity theory and what an activity system is, to be used directly. Hence, its usefulness for direct usage by non-researcher stakeholders in supporting communication is limited. In order to have an artefact more directly usableby all stakeholders, we performed a different topic clustering, aiming at a more easily interpretable view of the adoption process.

\section{Activity: adoption of an LA innovation in a classroom}

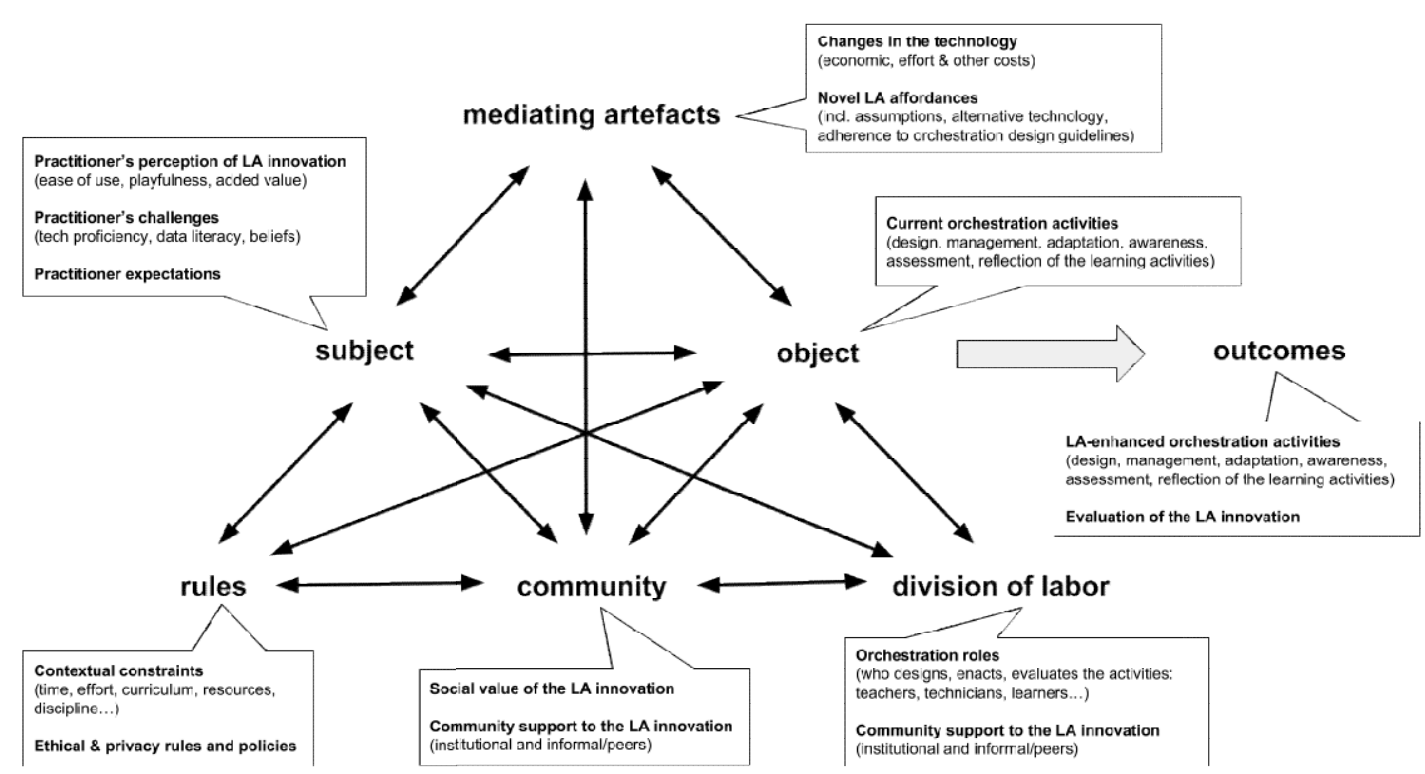

Figure 3. OrLA framework representing LA adoption as a sociocultural activity system.

One such simpler interpretation is to think of the adoption as an appraisal and decision process (i.e., classroom stakeholders deciding "should I adopt this new LA tool in my classroom?"). As we saw in the literature review above, such appraisal and decision (based on costs and affordances) are a recurrent notion across sources in all four categories of papers analysed. In order to perform this cost-benefit appraisal, the stakeholders need to reflect upon (and, most probably, exchange information about) crucial aspects of the innovation and the context, which can be grouped along a reduced number of themes (to help organise the large number of topics identified). Figure 4 represents this alternative clustering process, from the literature review categories and individual papers, to the 23 emergent topics and seven larger themes that make up this simplified decision process. 


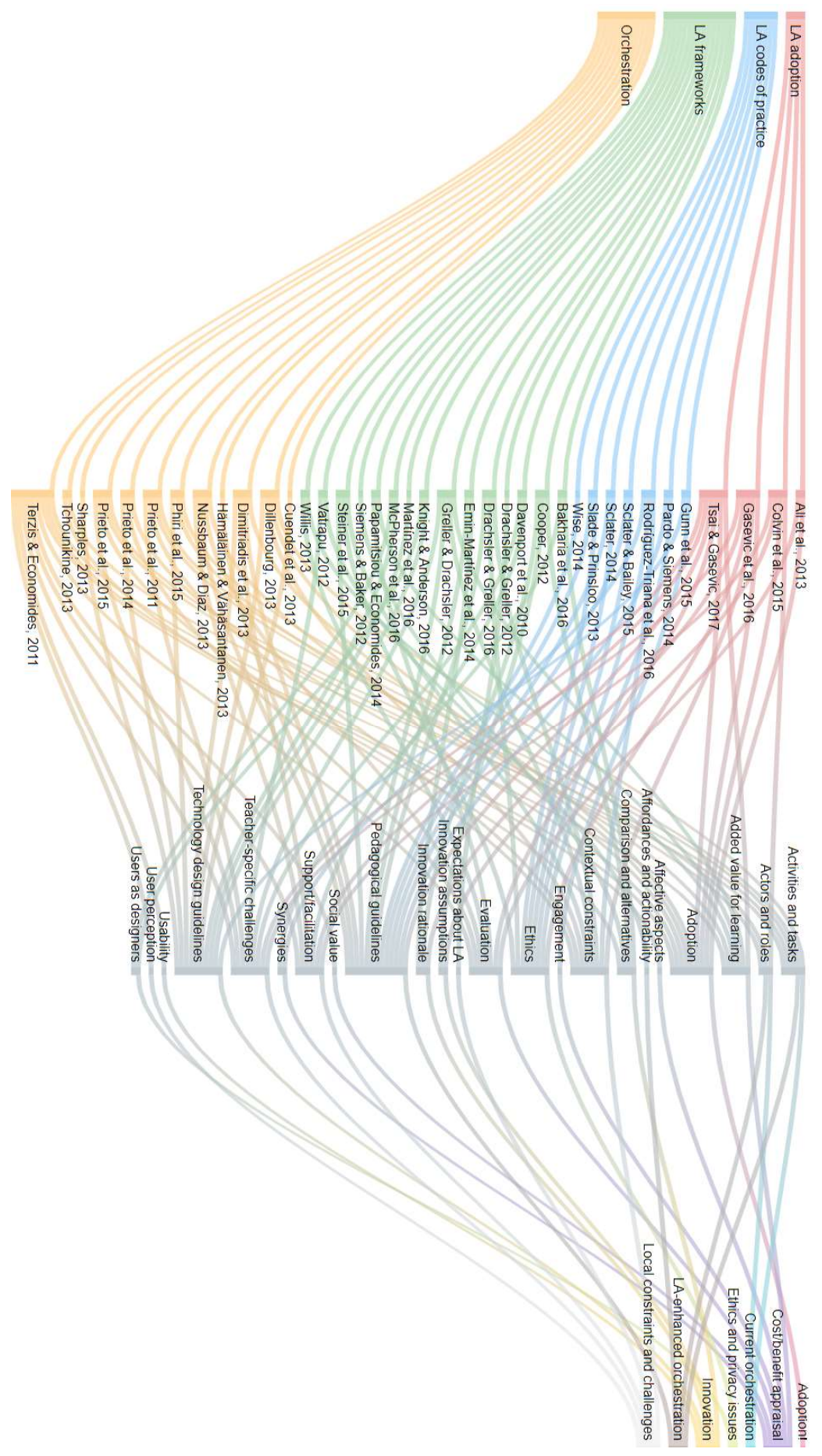

Figure 4. Literature review and topical mapping to simplified OrLA framework notions. The first three layers of the diagram are identical to those in Figure 2; only the last level of grouping is different. A larger, interactive version is available at https://prisan-tlu.shinyapps.io/sankeyDiagrams/. 
The resulting framework, represented graphically in Figure 5, defines seven main areas to touch upon: local constraints and challenges; current orchestration/practice; new, LA-enhanced orchestration/practice; characteristics of the LA innovation itself; ethics and privacy issues. The sixth area involves stakeholders reaching common ground on the five previous ones and making an informed appraisal and joint decision on whether to adopt the LA technology, or what form the innovation should take in order to be adopted. Finally, a seventh area relates to whether the innovation is actually adopted in the classroom's practice.

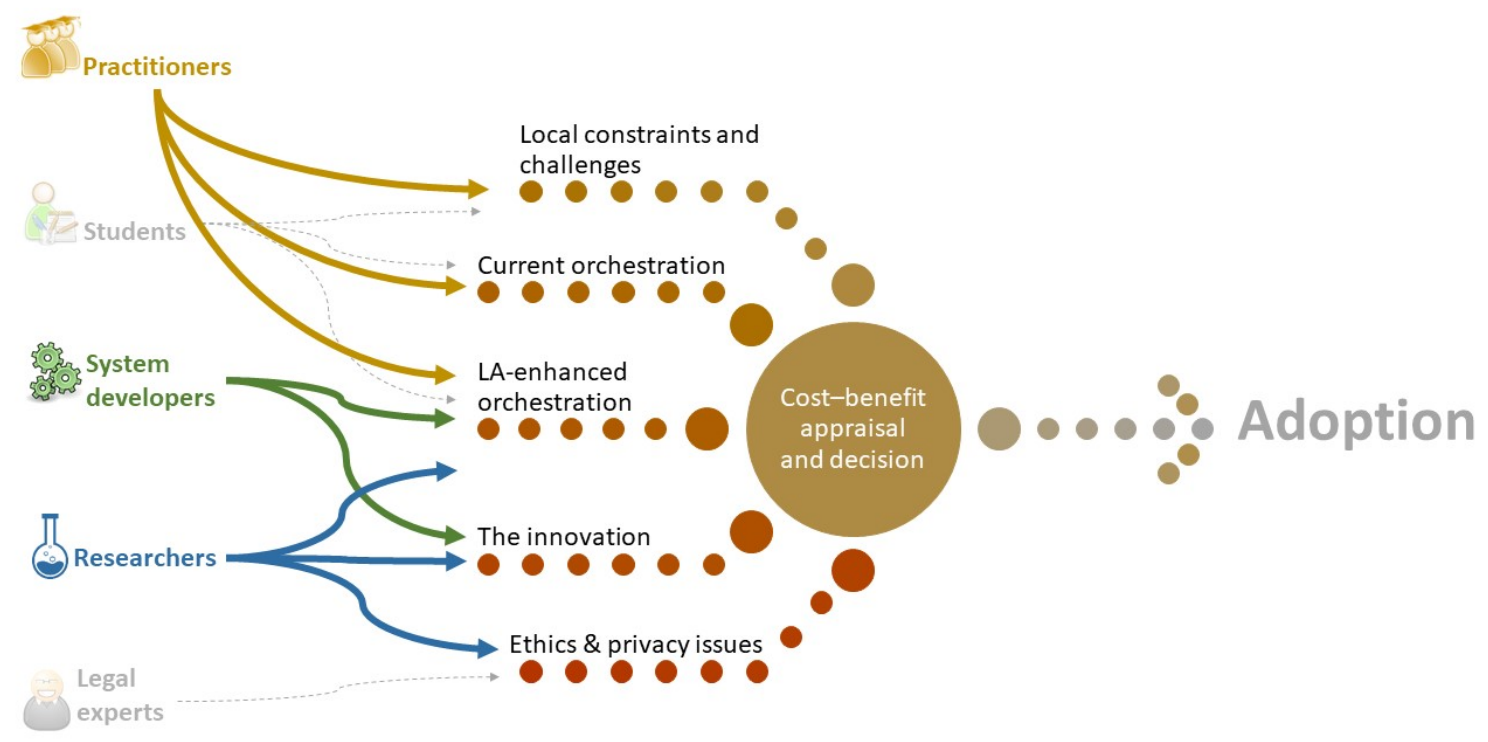

Figure 5. Simplified OrLA framework, including the specialised knowledge of stakeholders about the various themes (left)

This second framework again can be used in LA adoption processes (both linear and/or iterative). A practitioner could, for instance, use these larger themes to structure consultations or interviews with researchers or system developers. Indeed, the following section provides further examples of how this framework is being used in real LA adoption processes.

\section{Supporting stakeholder communication: the stakeholder forms}

While the conceptual frameworks presented above can be useful, there are limits to the usefulness of such abstract frameworks for direct use in inter-stakeholder conversations, as it may be difficult to map the abstract themes to the concrete reality of the classroom. We thus developed a set of forms that aim to support the communication process among the three main stakeholders that are involved in most LA adoption scenarios: researchers, LA system developers, and teachers. However, as suggested by the framework in Figure 5, this idea could also be extended to other stakeholders, such as students or legal experts. An illustrative representation of these forms is presented in Figure 6, and a full electronic version of them is available for detailed inspection at https://tinyurl.com/OrLA-forms.

The communication process implied by these forms involves each stakeholder filling in a form with questions about the topics that each of them is most likely to have more knowledge about compared to other stakeholders (see Figure 6, top-left part of each form, marked as "1"). Then, each (incomplete) form is in turn passed to the other stakeholders, who read the information provided, and bring on comments and contrasting pieces of knowledge, to unearth potential tensions and conflicts (steps marked "2" and " 3 "). Finally, all stakeholders come together and discuss the content of the forms, and decide about the adoption (marked "4"). 
For instance, the form that the teacher completes initially contains questions regarding what awareness and assessment processes (e.g., monitoring of students' work - one of the classic orchestration activities) are performed in the concrete educational context before introducing LA (including when they are performed, supporting technologies, or time constraints). In the same form, system developers would note how this would change once the LA tool is introduced (e.g., identifying whether the practices or assessment criteria would have to change, or potential conflicts with the local time constraints). Later on, the researcher would add information on whether the changed practices and tools are still compatible with the theoretical and pedagogical assumptions of the innovation. Then, the tensions and opportunities detected in this and the other forms can be used during inter-stakeholder discussions and adoption decisions.

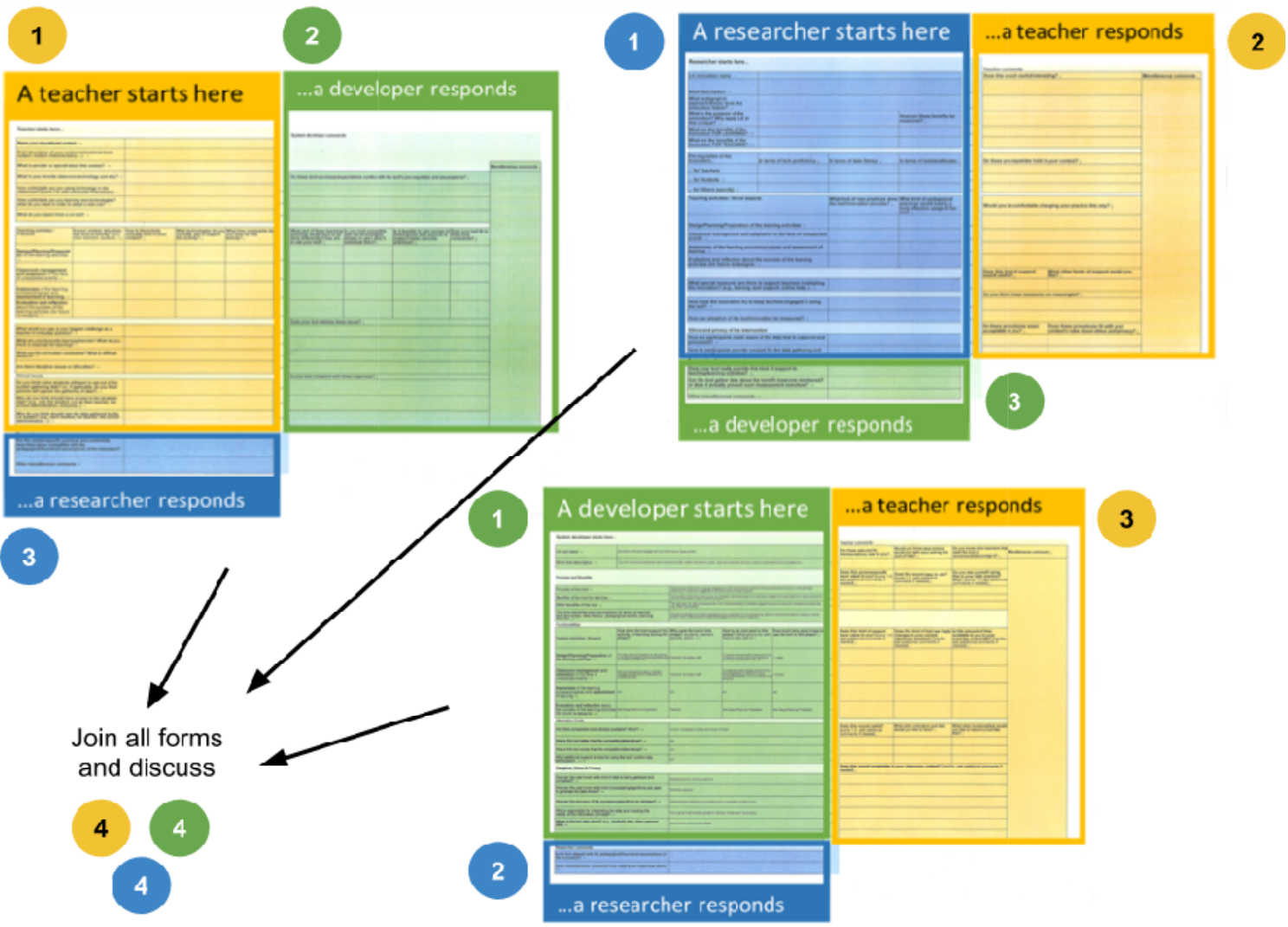

Figure 6. Stakeholder forms based on the OrLA framework. Numbers denote the sequence in which each stakeholder interacts with a form.

\section{OrLA in action: three illustrative examples}

To help the reader understand the usefulness of the OrLA frameworks and artefacts presented above, we describe below three authentic examples of use within LA development and adoption processes in three countries.

\section{Estonia: Using the simplified framework in stakeholder interviews}

In the context of a research project on how to support the co-creation of educational innovations using LA(Ruiz-Calleja, Rodríguez-Triana, Prieto, Poom-Valickis, \& Ley, 2017), simple LA tools are being piloted 
with a few volunteer teachers, in university courses in which the teachers want to introduce a certain pedagogical innovation. In this context, the simplified OrLA framework has been used to structure the conversations and semi-structured interviews with teachers, both before and after the classroom usage of the LA tools. In this project, OrLA has been useful to establish a dialogue that invites these volunteering teachers to understand the technology and the associated innovation, and whether such innovation would be adopted once the initial excitement wears off. For researchers and system developers, these OrLA-based interviews have served to delve deeper in understanding the local constraints and to derive modifications needed in later iterations of the LA technology, and the likelihood that teachers will want to use it for next year's courses.

Figure 7 depicts the (anonymised) interview guide used by a researcher-developer to talk with one of the participant practitioners. This practitioner had used a simple LA tool (a dashboard displaying live data from several questionnaires used during a lesson) to enable a new practice of more frequent formative feedback and discussion. The interview took place afterthe practitioner had used the LA tool in a few sessions of her course. The interview guided both stakeholders in reviewing relevant pieces of information dealing with the themes in the OrLA simplified view. These include, for instance, the intended benefit of increased student engagement, any learning benefits, but also the costs entailed - all under the theme of cost-benefit appraisal (see the "Cost-benefit appraisal" label and arrows in Figure 7).

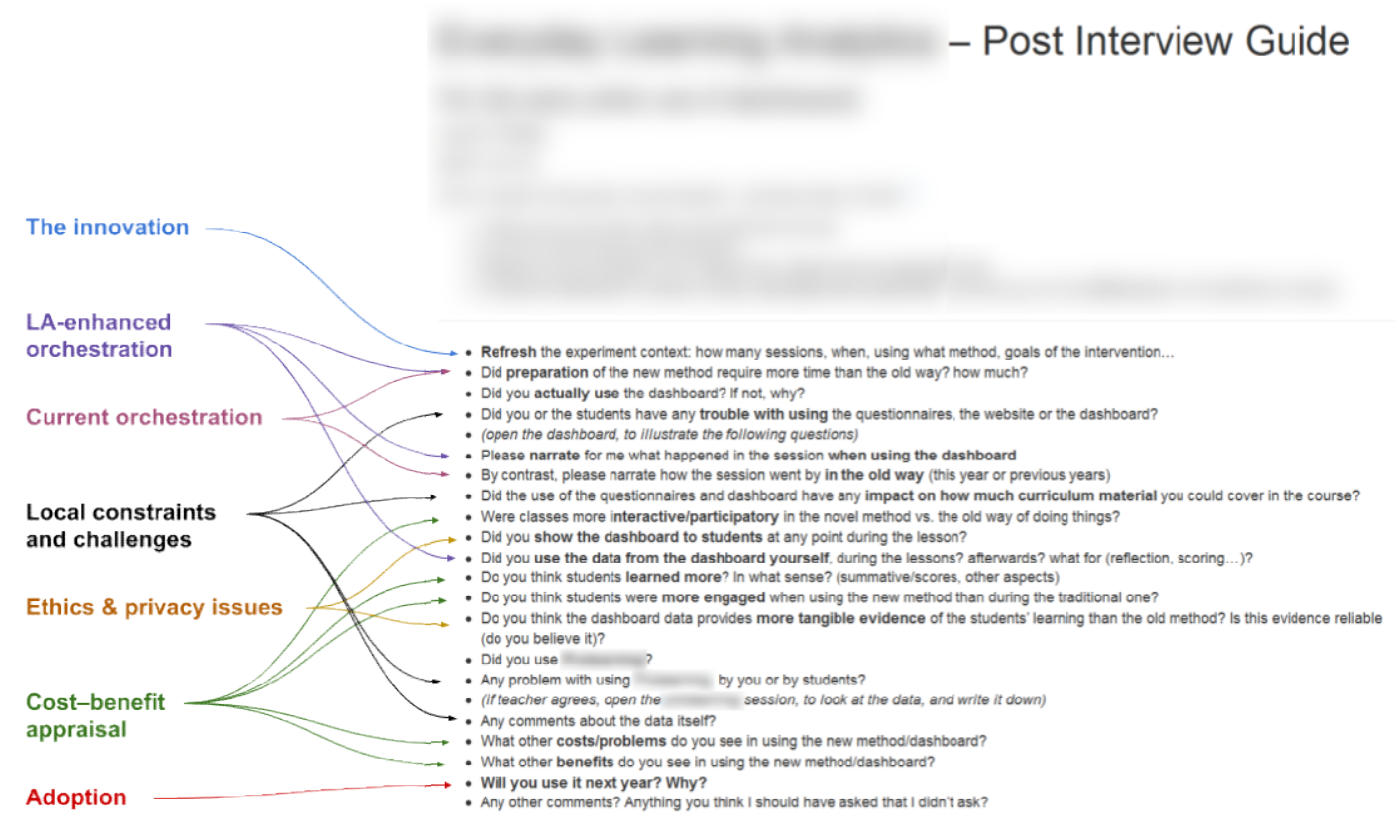

Figure 7. Teacher interview guide used at a small-scale LA pilot, marking the simplified OrLA framework themes used to structure the questions

\section{Australia: Using stakeholder forms in an LA implementation case}

The OrLA framework has also been useful in the context of an ongoing project to develop an awareness tool to be used in debriefing sessions after simulation-based learning in healthcare university settings (see Figure 8 , left). The goal of the debriefing tool is to use the data from multimodal LA(Ochoa, 2017) to support teacher-led reflection in the classroom, but also independent work by students, who can access the tool online (see initial prototype in Figure 8, right).

This project is conducted as a collaboration between an LA research group and the local School of Nursing at an Australian university. In this context, the main stakeholders in the conversation about the design, 
development and adoption of the aforementioned LA tool included two developers/technicians (D1 and D2), one course coordinator (or teacher, T), a simulation manager and a simulation researcher (R1, R2). The OrLA stakeholder formshave been used in the initial stages of the project to generate an understanding of the different (and sometimes, conflicting) perspectives that these stakeholders had.

Due to the logistic and scheduling restrictions of the stakeholders, these five actors preferred to fill in their initial input to the stakeholder forms individually, and then, in a second round of inputs, responded to each the other's forms, also individually. Only then, in a third round, did stakeholders actually meet and discuss their different perspectives.
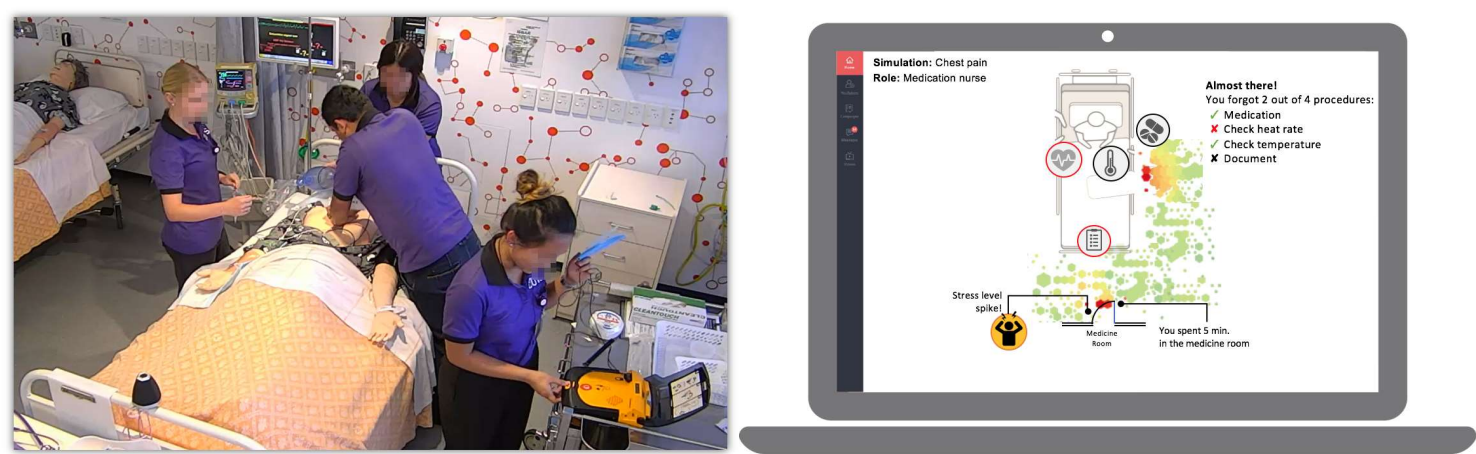

Figure 8. Authentic LA project where the OrLA forms have been put into practice. Left: the learning situation that teachers want to improve is the assessment of healthcare simulations. Right: an initial prototype of a reflection tool to highlight simulation mistakes.

Overall, the stakeholder forms were effective in allowing the different actors to speak up, as expressed by two of the nursing researchers:"[the forms] give opportunities for people of different disciplines to voice their thoughts on all aspects of the given task"[R2] and "put together multiple perspectives of the team in a structured way" [R1]. The teacher found it most useful to "share information among the team members [with the goal of] improving practice and student learning, which often does not naturally occur" [T]. Developers/technicians, however, did not fully understand the orchestration-related questions, but still expressed that they would like to know more about the teaching responsibilities, as they have a clear impact in the system they implement. It should be noted that this LA implementation project is still in a very early phase, and hence the stakeholder forms may be even more useful in later phases of the project, when the LA tool and intervention are more fully defined.

\section{Spain: Using stakeholder forms in an LA workshop with different stakeholders}

The OrLA frameworks and communication tools presented above are designed mainly to support an ongoing process of adoption or implementation of LA innovations (as the two examples above illustrate). These conceptual tools, however, can also be used for pedagogical purposes, taking a more long-term perspective: to help different stakeholders think about LA innovations in general, in the future.

This approach was taken in the context of a workshop on the topic of LA, which attracted LA researchers, LA-interested teachers and LA system developers. The workshop took place in Spain in 2016. Thirteen participants (most of them Spanish and representing researchers, teachers, and developers) gathered at this 90minute event. The goal of the event was to discuss the adoption of concrete LA tools (provided by the participant researchers and developers) in particular authentic educational settings (represented by the participant teachers). The workshop activities included (a) an introduction of the problem of LA adoption and the OrLA simplified view; (b) groupwork in multi-stakeholder teams of 3 or 4 people (including at least one person in each role), in which they filled in the OrLA stakeholder forms and passed them on to the other stakeholders in the team to complete; (c) discussion on the shared information, and the reaching of a final 
decision on whether each concrete LA tool should be adopted in each particular classroom-level setting; and (d) wrap-up and feedback about the framework and the forms themselves.

Although the 90-minute format proved too short to use the comprehensive stakeholder forms in their entirety, participant stakeholders were enthusiastic about the way OrLA structured the conversation and considered the perspectives of multiple actors - with some participants asking for more information to use it in their own research and development right away. Rather than yes/no decisions, the workshop's exercise yielded "starting points for adoption" [P3], detecting needs for further integration into the existing tool and practice ecosystem, and further iterations in the adoption process, as very often "lots of adaptations and development [during the adoption process] are needed" [P1]. The workshop also prompted proposals of extending the forms: for instance, some participants suggested that "students should be included" [P2] as another very relevant stakeholder in the process. A participantalso suggested highlighting "key points in every section" [P6], for such cases in which time is very limited.

\section{Discussion and future work}

This paper started out by highlighting one of the main issues identified in the emergent literature about the adoption of LA innovations: the importance (and difficulty) of communication between the different stakeholders involved in the process of adopting an LA innovation at the classroom level (e.g., teachers, researchers, or technology developers). After a review of four areaswithin LA and orchestration-related literature, we proposed the OrLA conceptual frameworks and tools, which can be used to scaffold such interstakeholder communication.

\section{Relationship to other adoption literature}

This synthesis of literature is the main contribution of this paper to the LA knowledge base. OrLA can be seen a flexible tool to support stakeholder communication in any kind of LA adoption process. The OrLA framework complements existing frameworks characterising LA adoption, such as the RAPID Outcome Mapping Approach (ROMA) used by Macfadyen et al. (2014), or the SHEILA framework derived from ROMA by Tsai et al. (2018). OrLA focuses explicitly on topics and stakeholders that are critical at the tactical level of everyday educational practice (as opposed to, e.g., a focus on institution-level policy and strategy), while keeping an explicit multi-stakeholder perspective. In particular, OrLA operationalises stakeholder engagement to support intended behavioural change (i.e., the purpose of LA use in classrooms) and analysis of institutional capacity, both defined within the SHEILA framework.

\section{Practical implications and change management}

The OrLA framework is a practical tool that enables change management towards the adoption of LA in classrooms. Challenges associated with change management when implementing technological innovations are well documented (Bates, 2000; Macfadyen \& Dawson, 2012). Although they evolve as social systems, educational organisations are naturally resistant to change (Kavanagh \& Ashkanasy, 2006; Kotter, 1996). Change management researchers suggest that conditions need to be created for participants to perceive change positively (Kotter \& Cohen, 2002), and these conditions need to "appeal to both the heart and the head" of the participants (Macfadyen \& Dawson, 2012, p. 23). The OrLA framework enables organisations to develop the desire to change in participants (Hiatt, 2006) after awareness of the potential value of LA is initially raised. Desire can be developed with OrLA through engagement in a dialogue with other relevant stakeholders with the aim of maximising the value proposition of using LA in classrooms. Future research should study the extent to which OrLA can create conditions for the development of this desire to change, and the role of OrLA in other change management activities that follow the development of desire to change (Hiatt, 2006), such as training opportunities to develop the skills needed to use analytics effectively in classroom practice and to reinforce such use.

\section{Theoretical implications}


From a theoretical standpoint, the OrLA artefacts presented in this paper can be seen as boundary objects to aid in the communication between the different stakeholder communities involved (Star \& Griesemer, 1989). Boundary objects have been studied in sociology, in the interaction between different communities, by noting how certain (physical or conceptual) artefacts play a critical role in this communication (Star, 1989). The notion has been widely applied in information systems (Huvila, Anderson, Jansen, McKenzie, \& Worrall, 2016), computer-supported collaborative work, and many other fields. It can also be linked to different communities of practice (Wenger, 1998) working on a common task (as it occurs in the case of LA adoption). The conceptual frameworks defined in Figures 3 and 5 can thus be considered ideal types, in terms of the boundary object taxonomy defined by Star and Griesemer (1989, p. 410):

[A] diagram, atlas or other description which in fact does not accurately describe the details of any one locality or thing [...] abstracted from all domains, and may be fairly vague [...] it serves as a means of communicating and cooperating symbolically - a 'good enough' road map for all parties.

Similarly, the OrLA stakeholder forms in Figure 6 represent a more concrete kind of boundary object that can be supportive of such communication, named standardised forms(Star \& Griesemer, 1989).

Although the boundary objects presented here can be used asis (as shown in the three illustrative international examples in the previous section), boundary objects cannot be designed to their last details. Their very nature is to be adapted and repurposed in contextualised practice by the stakeholder communities that use them (Star \& Griesemer, 1989). In that sense, our present proposal is just a starting point for stakeholders to adapt to their particular contexts. This adaptation is indeed already apparent in the customised interview guide of the example from Estonia, or the simplifications suggested by stakeholders in the workshop held in Spain.

In a similar way, it should be noted that these boundary objects (both the conceptual frameworks and the stakeholder forms) do not prescribe a design or communication sequence, or a leading stakeholder. Instead, they are meant to serve as vehicles for an iterative and collaborative inter-stakeholder conversation, adapted to the constraints of each specific context. Any stakeholder may kickstart the communication process, even if the three illustrative scenarios shown in this paper were initiated by researchers.

\section{Limitations}

This emergent quality of the OrLA boundary objects does not excuse us, however, from evaluating their effectiveness in supporting communication and iteratively developing them (a limitation of our research at this stage). Indeed, the illustrative examples above are part of an ongoing evaluation effort to assess the added value of the OrLA frameworks and tools, taking place in multiple countries. These efforts include not only adoption processes led by the authors of this paper, but also by external researchers in the frame of larger LA adoption efforts, such as the LALA project to develop and adopt LA innovations in Latin American higher education institutions (https://www.lalaproject.org/). Despite these efforts, the true proof of the frameworks' usefulness will be their wider usage in research and innovation, either asis or in locallyadapted forms, in grassroots or institution-driven LA adoption processes. To this end, we are already organising scientific events to disseminate and discuss these boundary objects, adapting and refining them with the help of the broader LA community (see, e.g., the OrLA workshop organised at the LAK'18 conference http://orla.utscic.edu.au/).

We should note other caveats and limitations of OrLA in its current form. One is the relatively narrow scope of the literature review performed, which did not exhaustively explore each and every topic related to LA adoption. For instance, although ethical and privacy issues are recognised as a topic of importance, our review did not include all the numerous recent works dealing with this topic in LA (e.g., Ifenthaler \& Tracey, 2016). Such deeper reviews of each of the topics and themes within OrLA would be very useful future work, to further detail or develop OrLA-based communication instruments. Another important caveat is the fact that, while our review was not restricted to a particular educational level, a large majority of the work done so far 
on LA and their adoption has taken place in higher education (see, e.g., Schwendimann et al., 2017), which may have induced a higher-education bias in OrLA.

\section{Future work}

Aside from our current work in the aforementioned real-world validation in LA adoption projects and community dissemination through workshops and other events, future work in this line of research includes the extension and development of other OrLA communication aids addressing the above-mentioned limitations. We also envision the alignment of the OrLA framework with other emergent trends such as responsible research and innovation(Wickson \& Carew, 2014): We believe that early user involvement and multi-stakeholder conversations have a crucial role in the LA research agenda, if we are to avoid dystopian visions of the application of analytics to educational settings (Griffiths, Brasher, Ferguson, Clow, \& Yuan, 2016). It is these conversations that the OrLA frameworks aim to support.

\section{Acknowledgements}

This research has been partially funded by the European Union in the context of CEITER and Next-Lab (Horizon 2020 Research and Innovation Programme, grant agreements no. 669074 and 731685), and through theErasmus+ program (588438-EPP-1-2017-1-EL-EPPKA2-KA, 562080-EPP-1-2015- BE-EPPKA3-PIFORWARD, 586120-EPP-1-2017-1-ES-EPPKA2-CBHE-JP, and 2017-1-NL01-KA203-035288). It has also been partially funded by the Spanish State Research Agency (AEI) and the European Regional Development Fund (TIN2014-53199-C3-2-R and TIN2017-85179-C3-2-R), the Regional Government of Castilla y León and the European Regional Development Fund (VA082U16), the Spanish Ministry of Science and Education (PRX17/00410), the Faculty of Education at Monash University, and the University of Valladolid (UVa).

\section{References}

Ali, L., Asadi, M., Gašević, D., Jovanović, J., \& Hatala, M. (2013). Factors influencing beliefs for adoption of a learning analytics tool: An empirical study. Computers \& Education, 62, 130-148. https://doi.org/10.1016/j.compedu.2012.10.023

Bakharia, A., Corrin, L., de Barba, P., Kennedy, G., Gaševic, D., Mulder, R., ... Lockyer, L. (2016). A conceptual framework linking learning design with learning analytics. In Proceedings of the Sixth International Conference on Learning Analytics \& Knowledge (pp. 329-338). New York, NY: ACM Press. https://doi.org/10.1145/2883851.2883944

Bates, T. (2000). Managing technological change: Strategies for college and university leaders (1st ed.). San Francisco, CA: Jossey-Bass.

Colvin, C., Rogers, T., Wade, A., Dawson, S., Gaševic, D., Buckingham Shum, S., \& Fisher, J. (2015). Student retention and learning analytics: A snapshot of Australian practices and a framework for advancement. Sydney: Australian Office for Learning and Teaching.

Cooper, A. (2012). A framework of characteristics for analytics(CETIS Analytics Series, Vol. 1, No. 7). Retrieved from http://publications.cetis.org.uk/2012/524

Cuendet, S., Bonnard, Q., Do-Lenh, S., \& Dillenbourg, P. (2013). Designing augmented reality for the classroom. Computers \& Education, 68, 557-569. https://doi.org/10.1016/j.compedu.2013.02.015

Davenport, T. H., Harris, J. G., \& Morison, R. (2010). Analytics at work: Smarter decisions, better results. Boston, MA: Harvard Business Press.

Dillenbourg, P. (2013). Design for classroom orchestration. Computers \& Education, 69, 485-492. https://doi.org/10.1016/j.compedu.2013.04.013

Dillenbourg, P., Järvelä, S., \& Fischer, F. (2009). The evolution of research in computer-supported collaborative learning: From design to orchestration. In N. Balacheff, S. Ludvigsen, T. de Jong, A. Lazonder, \& S. Barnes (Eds.), Technology-enhanced learning: Principles and products (pp. 3-19). Dordrecht, Netherlands: Springer.https://doi.org/10.1007/978-1-4020-9827-7_1

Dimitriadis, Y., Prieto, L. P., \& Asensio-Pérez, J. I. (2013). The role of design and enactment patterns in orchestration: Helping to integrate technology in blended classroom ecosystems. Computers \& Education,69, 496-499. https://doi.org/10.1016/j.compedu.2013.04.004 
Drachsler, H., \& Greller, W. (2012). The pulse of learning analytics understandings and expectations from the stakeholders. In Proceedings of the 2nd International Conference on Learning Analytics and KnowledgeLAK '12 (pp. 120-129). New York, NY: ACM Press. https://doi.org/10.1145/2330601.2330634

Drachsler, H., \& Greller, W. (2016). Privacy and analytics: It's a DELICATE issue a checklist for trusted learning analytics. In Proceedings of the Sixth International Conference on Learning Analytics \& Knowledge (pp. 89-98).New York, NY: ACM Press.https://doi.org/10.1145/2883851.2883893

Emin-Martinez, V., Hansen, C., Rodríguez-Triana, M. J., Wasson, B., Mor, Y., Ferguson, R., \& Pernin, J.-P. (2014). Towards teacher-led design inquiry of learning. E-Learning Papers. Special Issue on Learning Analytics and Assessment, 36, 3-14. Retrieved from http://oro.open.ac.uk/39353/1/Teacher\%201ed\%20design\%20inquiry.pdf

Engeström, Y. (1987). Learning by expanding: An activity-theoretical approach to developmental research. Helsinki, Finland: Orienta-Konsultit.

Ferguson, R., Brasher, A., Clow, D., Cooper, A., Hillaire, G., Mittelmeier, J., ... Vuorikari, R. (2016). Research evidence on the use of learning analytics: Implications for education policy (Joint Research Centre Science for Policy Report, EUR 28294 EN).Luxembourg City: Publications Office of the European Union. https://doi.org/10.2791/955210

Ferguson, R., Macfadyen, L. P., Clow, D., Tynan, B., Alexander, S., \& Dawson, S. (2014). Setting learning analytics in context: Overcoming the barriers to large-scale adoption. Journal of Learning Analytics, 1(3), 120-144. https://doi.org/10.18608/jla.2014.13.7

Gašević, D., Dawson, S., \& Pardo, A. (2016). How do we start? State and directions of learning analytics adoption. Oslo, Norway: International Council for Open and Distance Education (ICDE).

Gašević, D., Dawson, S., \& Siemens, G. (2015). Let's not forget: Learning analytics are about learning. TechTrends, 59(1), 64-71. https://doi.org/10.1007/s11528-014-0822-x

Greller, W., \& Drachsler, H. (2012). Translating learning into numbers: A generic framework for learning analytics. Educational Technology \& Society, 15(3), 42-57. Retrieved fromhttps://www.jets.net/ETS/journals/15 3/4.pdf

Griffiths, D., Brasher, A., Ferguson, R., Clow, D., \& Yuan, L. (2016). “Visions of the Future”, Horizon Report (Learning Analytics Community Exchange Public Deliverable D3.2). Retrieved from http://www.laceproject.eu/deliverables/d3-2-visions-of-the-future-2/

Gunn, C., McDonald, J., Donald, C., Milne, J., Nichols, M., \& Heinrich, E. (2015). A practitioner's guide to learning analytics. InT. Reiners, B.R. von Konsky, D. Gibson, V. Chang, L. Irving, \& K. Clarke (Eds.), Globally connected, digitally enabled. Proceedings of Ascilite 2015 (pp. 672-675). Retrieved from http://www.2015conference.ascilite.org/wp-content/uploads/2015/11/ascilite-2015-proceedings.pdf

Hämäläinen, R., \& Vähäsantanen, K. (2011). Theoretical and pedagogical perspectives on orchestrating creativity and collaborative learning. Educational Research Review, 6(3), 169-184. https://doi.org/10.1016/j.edurev.2011.08.001

Hiatt, J. (2006). ADKAR: A model for change in business, government, and our community (1st ed.). Loveland, CO: Prosci Learning Center Publications.

Huvila, I., Anderson, T. D., Jansen, E. H., McKenzie, P., \& Worrall, A. (2016). Boundary objects in information science. Journal of the Association for Information Science and Technology, 68(8), $1807-$ 1822. https://doi.org/10.1002/asi.23817

Ifenthaler, D., \& Tracey, M. W. (2016). Exploring the relationship of ethics and privacy in learning analytics and design: implications for the field of educational technology. Educational Technology Research and Development, 64(5), 877-880. https://doi.org/10.1007/s11423-016-9480-3

Kavanagh, M. H., \& Ashkanasy, N. M. (2006). The impact of leadership and change management strategy on organizational culture and individual acceptance of change during a merger. British Journal of Management, 17(S1), S81-S103. https://doi.org/10.1111/j.1467-8551.2006.00480.x

Kitchenham, B. (2004). Procedures for performing systematic reviews (Keele University Technical Report TR/SE-0401). Keele, UK: Keele University. Retrieved fromhttp://www.scm.keele.ac.uk/ease/sreview.doc

Knight, S., \& Anderson, T. D. (2016). Action-oriented, Accountable, and inter (Active) Learning Analytics for Learners. In S. Bull, B. M. Ginon, J. Kay, M. D. Kickmeier-Rust, \&M. D. Johnson (Eds.),Proceedings of the LAK 2016 Workshop on Learning Analytics for Learners (pp. 47-51). Retrieved from http://ceurws.org/Vol-1596/paper8.pdf

Kotter, J. P. (1996). Leading change. Boston, MA: Harvard Business Review Press. 
Kotter, J. P., \& Cohen, D. S. (2002). The heart of change: Real-life stories of how people change their organizations. Boston, MA: Harvard Business Review Press.

Macfadyen, L. P., \& Dawson, S. (2012). Numbers are not enough. Why e-learning analytics failed to inform an institutional strategic plan. Journal of Educational Technology \& Society, 15(3), 149-163.Retrieved from https://www.j-ets.net/ETS/journals/15_3/11.pdf

Macfadyen, L. P., Dawson, S., Pardo, A., \& Gasevic, D. (2014). Embracing big data in complex educational systems: The learning analytics imperative and the policy challenge. Research \& Practice in Assessment, 9, 17-28. Retrieved fromhttp://www.rpajournal.com/dev/wp-content/uploads/2014/10/A2.pdf

Martinez-Maldonado, R., Schneider, B., Charleer, S., Shum, S. B., Klerkx, J., \& Duval, E. (2016). Interactive surfaces and learning analytics: Data, orchestration aspects, pedagogical uses and challenges. In Proceedings of the Sixth International Conference on Learning Analytics \& Knowledge- LAK '16 (pp. 124-133). New York, NY: ACM Press. https://doi.org/10.1145/2883851.2883873

McPherson, J., Tong, H. L., Fatt, S. J., \& Liu, D. Y. (2016). Student perspectives on data provision and use: starting to unpack disciplinary differences. In Proceedings of the Sixth International Conference on Learning Analytics \& Knowledge (pp. 158-167).New York, NY: ACM Press. https://doi.org/10.1145/2883851.2883945

Nussbaum, M., \& Diaz, A. (2013). Classroom logistics: Integrating digital and non-digital resources. Computers \& Education, 69, 493-495. https://doi.org/10.1016/j.compedu.2013.04.012

Ochoa, X. (2017). Multimodal learning analytics. In C. Lang, G. Siemens, A. Wise, \& D. Gasevic (Eds.), Handbook of learning analytics (pp. 129-141). Society for Learning Analytics Research (SoLAR). https://doi.org/10.18608/hla17.011

Papamitsiou, Z., \& Economides, A. A. (2014). Learning analytics and educational data mining in practice: A systematic literature review of empirical evidence. Journal of Educational Technology \& Society, 17(4), 49-64. Retrieved fromhttps://www.j-ets.net/ETS/journals/17 4/4.pdf

Pardo, A., \& Siemens, G. (2014). Ethical and privacy principles for learning analytics. British Journal of Educational Technology: Journal of the Council for Educational Technology,45(3), 438-450. https://doi.org/10.1111/bjet.12152

Phiri, L., Meinel, C., \& Suleman, H. (2016). Streamlined orchestration: An orchestration workbench framework for effective teaching. Computers \& Education, 95, 231238.https://doi.org/10.1016/j.compedu.2016.01.011

Prieto, L. P., Dimitriadis, Y., Asensio-Pérez, J. I., \& Looi, C. K. (2015). Orchestration in learning technology research: Evaluation of a conceptual framework. Research in Learning Technology, 23(1), 28019. https://doi.org/10.3402/rlt.v23.28019

Prieto, L. P., Holenko-Dlab, M., Abdulwahed, M., Gutiérrez, I., \& Balid, W. (2011). Orchestrating technology enhanced learning: A literature review and a conceptual framework. International Journal of Technology-Enhanced Learning (IJTEL),3(6), 583-598.https://doi.org/10.1504/IJTEL.2011.045449

Prieto, L. P., Wen, Y., Caballero, D., \& Dillenbourg, P. (2014). Review of augmented paper systems in education: An orchestration perspective. Journal of Educational Technology \& Society, 17(4), 169185.Retrieved from https://www.j-ets.net/ETS/journals/17 4/11.pdf

Rodríguez-Triana, M. J., Martínez-Monés, A., \& Villagrá-Sobrino, S. (2016). Learning analytics in smallscale teacher-led innovations: Ethical and data privacy issues. Journal of Learning Analytics, 3(1), 4365.https://doi.org/10.18608/jla.2016.31.4

Roschelle, J., Dimitriadis, Y., \& Hoppe, U. (2013). Classroom orchestration: Synthesis. Computers \& Education, 69, 523-526. https://doi.org/10.1016/j.compedu.2013.04.010

Ruiz-Calleja, A., Rodríguez-Triana, M. J., Prieto, L. P., Poom-Valickis, K., \& Ley, T. (2017). Towards a Living Lab to support evidence-based educational research and innovation. In Á. Hernández-García, M. Caeiro-Rodríguez, \& P. J. Muñoz-Merino (Eds.), Proceedings of the Learning Analytics Summer Institute Spain 2017 (pp. 31-38).Retrieved from http://ceur-ws.org/Vol-1925/paper04.pdf

Schwendimann, B. A., Rodriguez-Triana, M. J., Vozniuk, A., Prieto, L. P., Boroujeni, M. S., Holzer, A., ... Dillenbourg, P. (2017). Perceiving learning at a glance: A systematic literature review of learning dashboard research. IEEE Transactions on Learning Technologies, 10(1), 30-41. https://doi.org/10.1109/TLT.2016.2599522

Sclater, N. (2014). Code of practice for learning analytics: A literature review of the ethical and legal issues (JISC Reviews Report). Retrieved from http://repository.jisc.ac.uk/5661/ 
Sclater, N., \& Bailey, P. (2015). Code of practice for learning analytics (JISC Guide). Retrieved from https://www.jisc.ac.uk/guides/code-of-practice-for-learning-analytics

Sharples, M. (2013). Shared orchestration within and beyond the classroom. Computers \& Education, 69 , 504-506. https://doi.org/10.1016/j.compedu.2013.04.014

Siemens, G., \& Baker, R. S. J. d. (2012). Learning analytics and educational data mining: Towards communication and collaboration. In Proceedings of the 2nd International Conference on Learning Analytics and Knowledge - LAK'12 (pp. 252-254). New York, NY, USA: ACM Press. https://doi.org/10.1145/2330601.2330661

Siemens, G., \& Long, P. (2011). Penetrating the fog: Analytics in learning and education. EDUCAUSE Review, 46(5), 30-40. Retrieved fromhttps://er.educause.edu/articles/2011/9/penetrating-the-fog-analyticsin-learning-and-education

Slade, S., \& Prinsloo, P. (2013). Learning analytics: Ethical issues and dilemmas. American Behavioral Scientist, 57(10), 1510-1529. https://doi.org/10.1177/0002764213479366

Star, S. L. (1989). The structure of ill-structured solutions: Heterogeneous problem-solving, boundary objects and distributed artificial intelligence. In M. Huhns (Ed.),Distributed artificial intelligence (Vol. 2, pp. 3754). San Francisco, CA: Morgan Kaufmann.

Star, S. L., \& Griesemer, J. R. (1989). Institutional ecology, translations and boundary objects: Amateurs and professionals in Berkeley's Museum of Vertebrate Zoology. Social Studies of Science, 19, 387420.https://doi.org/10.1177/030631289019003001

Steiner, C. M., Kickmeier-Rust, M. D., \& Albert, D. (2016). LEA in private: A privacy and data protection framework for a learning analytics toolbox. Journal of Learning Analytics, 3(1), 6690.https://doi.org/10.18608/jla.2016.31.5

Tchounikine, P. (2013). Clarifying design for orchestration: Orchestration and orchestrable technology, scripting and conducting. Computers \& Education, 69, 500-503. https://doi.org/10.1016/j.compedu.2013.04.006

Terzis, V., \& Economides, A. A. (2011). The acceptance and use of computer based assessment. Computers \& Education, 56(4), 1032-1044.https://doi.org/10.1016/j.compedu.2010.11.017

Tsai, Y.-S., \& Gasevic, D. (2017). Learning analytics in higher education - challenges and policies: A review of eight learning analytics policies. In Proceedings of the Seventh International Learning Analytics \& Knowledge Conference - LAK' 17 (pp. 233-242). New York, NY: ACM Press. https://doi.org/10.1145/3027385.3027400

Tsai, Y.-S., Moreno-Marcos, P. M., Tammets, K., Kollom, K., \& Gašević, D. (2018). SHEILA policy framework: Informing institutional strategies and policy processes of learning analytics. In Proceedings of the 8th International Conference on Learning Analytics and Knowledge - LAK '18 (pp. 320-329). New York, NY: ACM Press. https://doi.org/10.1145/3170358.3170367

Vatrapu, R. K. (2012). Towards semiology of teaching analytics. In R. Vatrapu, W. Halb, \& S. Bull (Eds.),Proceedings of the Workshop Towards Theory and Practice of Teaching Analytics 2012. Retrieved from http://ceur-ws.org/Vol-894/paper1.pdf

Wenger, E. (1998). Communities of practice: Learning, meaning, and identity. Cambridge, UK: Cambridge University Press.

Wickson, F., \& Carew, A. L. (2014). Quality criteria and indicators for responsible research and innovation: Learning from transdisciplinarity. Journal of Responsible Innovation, 1(3), 254-273. https://doi.org/10.1080/23299460.2014.963004

Willis III, J. E., Campbell, J., \& Pistilli, M. (2013). Ethics, big data, and analytics: A model for application.EDUCAUSE Review Online. Retrieved from https://er.educause.edu/articles/2013/5/ethics-bigdata-and-analytics-a-model-for-application

Wise, A. F. (2014). Designing pedagogical interventions to support student use of learning analytics. In Proceedings of the Fourth International Conference on Learning Analytics and Knowledge - LAK '14 (pp. 203-211). New York, NY: ACM Press. https://doi.org/10.1145/2567574.2567588

Corresponding author: Luis P. Prieto, 1prisan@tlu.ee 
Australasian Journal of Educational Technology (C) 2019.

Please cite as: Prieto, L. P., Rodríguez-Triana, M. J., Martínez-Maldonado, R., Dimitriadis, Y., \& Gašević, D. (2019). Orchestrating learning analytics (OrLA): Supporting inter-stakeholder communication about adoption of learning analytics at the classroom level. Australasian Journal of Educational Technology, 35(4). https://doi.org/10.14742/ajet.4314 